\title{
Perempuan Berhijab dalam Konten Hijab Profile di Portal Wolipop: Analisis Semiotika Roland Barthes
}

\author{
Umi Khoirum \\ Universitas Islam Negeri Sunan Kalijaga Yogyakarta, Indonesia
}

Korespodensi dengan Penulis:

Umi Khoirum : 082345058286

E-mail: umi.bkl16@gmail.com

Keywords:

Hijab Muslim;

Hijab profile,

Roland barthes, and, Online

media

\section{Abstract}

Hijab is currently interpreted as part of women's fashion, to complement the beauty of clothes worn everyday. Many factors have caused a shift in the meaning of hijab for women. Some of the factors include trends. This study aims to reveal the role of the media, especially in the Wolipop portal, as an online media that packages women's lives in various aspects including the hijab profile in building the trend of women's hijab. In an effort to reveal this shift, the writer uses the theory of Roland Barthes as a knife to analyze the depiction of hijab women. The data were collected using purposive sampling method of articles on the hijab profile content in Wolipop. Based on the research results, it is known that in its development, the media presents women who are able to make the hijab not only a sign of Muslim women, but women who wear hijab have been able to appear in the public with various achievements that have led to the latest hijab fashion models. And online media consciously package how women are free to express themselves with their hijab according to their profession, age, interests and preferences.

\begin{abstract}
Abstrak
Hijab saat ini dimaknai bagian dari fashion perempuan untuk melengkapi keindahan pakaian yang dikenakan sehari-hari. Banyak faktor yang menyebabkan pergeseran makna hijab bagi perempuan. Beberapa faktor diantaranya adalah trend. Penelitian ini bertujuan untuk mengungkap, bagaimana peran media khususnya pada portal Wolipop, sebagai salah satu media online yang mengemas kehidupan perempuan pada berbagai aspek, termasuk hijab profile dalam membangun trend hijab perempuan. Sebagai upaya mengungkap pergeseran tersebut penulis menggunakan teori Roland Barthes sebagai pisau analisis penggambaran perempuan berhijab, data dikumpulkan dengan metode Purposive sampling artikel pada konten hijab profile di Wolipop. Berdasarkan hasil penelitian diketahui bahwa pada perkembangannya, media menghadirkan perempuan berhijab yang
\end{abstract}


mampu menjadikan hijab bukan saja tanda perempuan muslim, melainkan perempuan berhijab telah mampu hadir ditengah publik dengan berbagai prestasi yang memunculkan model-model hijab fashion terbaru. Media online secara sadar mengemas bagaimana perempuan bebas berekspresi dengan hijabnya sesuai dengan profesi, usia, minat dan kesukaan perempuan.

\section{PENDAHULUAN}

Pakaian menjadi salah satu aspek yang mengalami perkembangan signifikan. Dewasa ini tidak jarang masyarakat mengklasifikasikan pakaian menjadi pakaian syar'i dan pakaian masa kini. Stigma akan kebaikan akhlak seseorang dapat dinilai dari cara berpakaaian masih sangat lekat dikalangan masyarakat, dan juga sangat kontras ditampilkan di media massa yang sering kali menggambarkan tokoh antagonis diperankan oleh perempuan yang berpenampilan modis, menggunakan make-up, perhisan dan yang pasti berpakaian menarik tanpa menutup aurat, sedangkkan yang berperan sebagai tokoh protagonis lebih sering di perankan oleh seorang yang menggunakan pakaian berhijab.

Secara etimologi hijab (حجاب) adalah kata dalam Bahasa Arab yang berarti menutupi. Pada beberapa negara yang berbahasa Arab, serta negara-negara Barat, kata hijab lebih sering merujuk kepada kerudung yang digunakan oleh perempuan muslim. Hijab menurut bahasa hijab adalah sesuatu yang menghalangi antara dua lainnya. Kata ini juga berarti penutup. ${ }^{1}$ Namun dalam keilmuan Islam, hijab lebih tepat merujuk kepada tata cara berpakaian yang pantas (modesty) sesuai dengan tuntunan agama. Secara syariat, hijab merupakan pakaian yang diwajibkan bagi perempuan muslim. Dalam QS Al-Ahzab ayat 59 disebutkan

“Wahai Nabi! Katakanlah kepada istri-istrimu, anak-anak perempuanmu, dan istri-istri orang mukmin, hendaklah mereka menutupkan jilbabnya keseluruh tubuh mereka. Yang demikian itu agar mereka lebih mudah untuk dikenali, sehingga mereka tidak diganggu. Allah Maha Pengampun dan juga Maha Penyayang."

Pemaknaan atas perempuan berhijab kini bukan sekadar tentang perempuan berhijab yang berlandaskan sebagai pakaian tertulis, atau pakaian yang berlandaskan aturan awalnya. Penggunaan hijab sebagian besar menggabungkan antara makna relegius dengan budaya yang ada. Unsur fashion dalam hijab mempengaruhi terbentuknya gaya hidup muslimah modern, menunjukkan bahwa gaya hijab menyesuaikan dengan fashion dan tidak lagi terpaku pada aturan hijab menurut agama. Sehingga hijab menjadi trend yang terus berkembang. fenomena perkembangan hijab fashion merupakan suatu tranformasi sosial yang menarik, pergeseran selera dan gaya perempuan muslim dalam berbusana mulai menjadi bagian dari industri

${ }^{1}$ M Quraish Shihab, Jilbab Pakaian Wanita Muslimah: Pandangan Ulama Masa Lalu dan Cendikiawan Kontemporer, (Jakarta : Lentera Hati, 2012). hlm. 78. 
fashion sejak akhir 1990-an dengan "kekayaan semiotis" fashion muslim bagaimana cara, corak, asesoris dan gaya perempuan muslim berpakaian. ${ }^{2}$

Berkembangnya hijab fashion tidak lepas dari berkembangnya media massa. Ada banyak faktor yang media jadikan konten dari hijab, seperti; bisnis hijab, inspirasi hijabers, model hijab, tutorial berhijab, hijab style, dan sebagainya. Gaya hidup beberapa pesohor yang berpengaruh digambarkan pada media sosial. Sehingga model, desainer, produser, redaktur, peneliti juga pecinta fashion hijab mendedikasikan pemikiran, tenaga serta ide dalam dunia fashion hijab sehingga menjadi tren hijab sendiri. Kemudahan mengakses, menyebarkan dan membagi kembali di media online menjadi sebab model hijab mudah diketahui oleh para perempuan.

Portal wolipop.com memiliki beberapa fitur yang sangat dekat kaitannya dengan perempuan, di antara Lifestyle, Most Populer, High Light, Fashion, Hijab, Beauty, Relationship, Living, Work and Monay, Horos Cope, dan Entertainment. Wolipop.com memperlihatkan bagaimana perempuan dan kegiatannya, perempuan dan eksistensi, perempuan dan keluarga, sahabat serta percintaan, perempuan dan fenomena terkini, serta perempuan dengan trend model terbarunya. Semua konten dikemas secara apik dan membuat pembaca terus mencari artikel-artikel yang dibutuhkannya. Begitu banyak kisah perempuan dan bahasa sekitarnya yang disajikan oleh portal Wolipop ini, mulai dari artikel ringan mengenai rasi perbintangan, gosip terhangat pasangan, pernikahan, kecantikan ala barat hingga hijab.

Penulis tertarik pada konten Hijab Profile yang terdapat pada salah satu fitur hijab di wolipop.com. Penulis ingin melihat bagaimana portal ini, dalam menyajikan hijab profile dengan penggambaran beberapa foto tokoh dalam suatu artikel yang menggambaran dari seorang yang menggunakan hijab (hijabers), yang seolah tidak memiliki batasan untuk tetap eksis meskipun menggunakan hijab. Serta menelisik bagaimana wollipop.com mengkontruksi perempuan berhijab dengan pemilihan topik, tokoh, dan kehiduppannya. Hijab profile merupakan salah satu tanda bahasa yang dapat berperan sebagai alat komunikasi yang menjelaskan identitas sosial, adat dan penggambaran sifat individu kepada para pembacanya.

Studi terdahulu milik Rudianto menjelaskan hijab yang semula dipandang bergaya kuno, tua, kampungan dan terkesan hanya menciptakan kebaikan, hijab Medan hadir untuk menepis hal tersebut dan membangun citra bahwa seorang perempuan berhijab, dapat bergaya stylish dan modern, hijab bukan sebatas kewajiban bagi perempuan muslim, namun menjadi trend yang digemari perempuan muslim, juga menyatakan bahwa hijab adalah citra wanita muslim. ${ }^{3}$

2 Ade Nur Istiani, "Kontruksi Makna Hijab Fashion bagi Moslem Fashion Blogger", Jurnal Kajian Komunikasi, Vol. 3, No. 1, 2015. hlm. 49.

${ }^{3}$ Khairunnisa Rudianto, "Trend Fashion Hijab Terhadap Konsep Diri Hijabers Komunitas Hijab Medan", Jurnal Interaksi . Vol. 1, No: 1, 2017. hlm 105-117. 
Selanjutnya Thadi menyatakan bahwa media melanggengkan citra perempuan yang dominan pada wilayah domestik. Media menjadikan pemirsa untuk mengatur dan mengelola lingkungan, atau secara ringkas penelitian ini mengungkap bahwa media turut andil dalam membentuk citra perempuan. Serta peneliti berharap media juga ikut serta membentuk citra, bahwa perempuan juga memiliki kemampuan yang sama dalam andil di wilayah publik. ${ }^{4}$ Kedua penelitian tersebut telah mengungkap bahwa media juga berperan dalam membentuk citra perempuan. Penulis akan membongkar portal Wolipop yang menyediakan konten hijab profile yang menjadi harapan dari peneliti terdahulu mengenai Citra perempuan memiliki kemampuan yang sama seperti laki-laki jika diberi kesempatan, penelitian ini dikemas dalam judul perempuan berhijab dalam konten hijab profil di portal Wolipop.

\section{METODE}

\section{Pendekatan dan Analisa}

Penelitian ini menggunakan pendekatan kualitatif. Teknik penentuan objek dalam penelitian ini adalah purposive sampling. Karakteristik dalam konten artikel hijab profile meliputi inspirasi wanita berhijab, motivasi berhijab, eksistensi perempuan berhijab, bisnis, perjuangan berhijab, maka Penulis mengambil mengambil lima artikel sebagai objek penelitian terjadi pada tabel 1. Sebagai pisau analisis menggunakan teori Roland Barthes. Kunci dari semiotika Roland Barthes terletak pada makna denotasi, konotasi dan mitos.

Skema 1. Semiotika Roland Barthes

\begin{tabular}{|c|c|c|}
\hline $\begin{array}{l}\text { 1. Signifier } \\
\text { (Penanda) }\end{array}$ & $\begin{array}{l}\text { 2. Signified } \\
\text { (Petanda) }\end{array}$ & \\
\hline \multicolumn{2}{|c|}{$\begin{array}{l}\text { 3. Denotative Sign } \\
\text { (Tanda Denotatife) }\end{array}$} & \multirow{2}{*}{$\begin{array}{c}\text { 5. Connotative } \\
\text { Signified } \\
\text { (Petanda Konotatif) }\end{array}$} \\
\hline \multicolumn{2}{|c|}{$\begin{array}{l}\text { 4. Connotative Signifier } \\
\text { (Penanda Konoatif) }\end{array}$} & \\
\hline \multicolumn{3}{|c|}{ 6. Connotative Sign (Tanda Konotatif) } \\
\hline
\end{tabular}

Sumber: dalam Sobur, $2013^{5}$

Menurut Cobley dan Jansz, sebagaimana dikutip dalam Alex Sobur, gambaran Barthes seperti terlihat diatas menunjukkan bahwa tanda denotatif (3) terdiri atas : penanda (1) dan petanda (2). Akan tetapi, pada saat bersamaan, tanda denotatif adalah juga penanda konotatif

\footnotetext{
${ }^{4}$ Robeet Thadi, Citra Perempuan dalam Media, Jurnal Ilmiah Syi'ar, Vol. 14 No. 1 2014. hlm. 27-38.

${ }^{5}$ Alex Sobur, Semiotika Komunikasi, (Bandung :PT. Remaja Rosdakarya, 2013). hlm. 69.
} 
(4). Dengan kata lain, hal tersebut merupakan unsur material hanya jika kita mengenal tanda "singa", barulah konotasi seperti harga diri, kegarangan, dan keberanian menjadi mungkin. Dalam pandagannya, tanda konotatif tidak sekedar memiliki makna tambahan tetapi juga mempunyai kedua bagian tanda denotatif yang melandasi keberadaannya. Inilah sumbangan terbesar Barthes bagi penyempurna semiologi Seussure yang berhenti pada penandaaan dalam tataran denotatif.

Studi Barthes tentang tanda bertumpu pada peran pembaca (the reader). Baginya, konotasi walaupun merupakan sifat asli tanda, membutuhkan keaktifan pembaca agar dapat berfungsi, atau yang sering disebut Barthes sebagai sistem pemaknaan tataran kedua, yang dibangun di atas sistem lain yang telah ada sebelumnya. Sistem kedua ini oleh Barthes disebut dengan connotatif yang di dalam Mythologies-nya secara tegas ia bedakan dan denotative atau system pemaknaan tataran pertama. ${ }^{6}$

Berikut model sistematis dalam menganalisis makna dan tanda-tanda. Fokus Barthes adalah gagasan tentang signifikasi dua tahap (two order of signification) seperti dibawah ini :

Skema 2. Model Sistem Roland Barthes

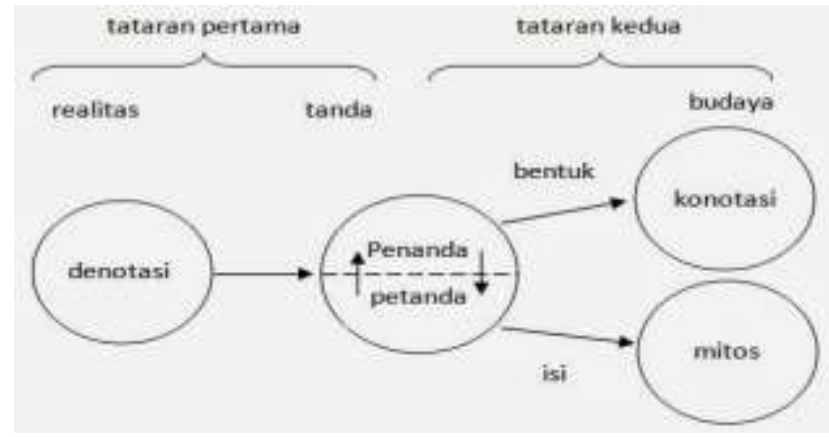

Sumber: dalam Sobur, 2013.7

Signifikasi tahap pertama merupakan hubungan antara signifier (penanda) dan signified (petanda) dalam sebuah tanda terhadap kualitas eksternal. Barthes menyebutnya dengan denotasi atau makna yang nyata dari tanda. Sedangkan konotasi adalah istilah Barthes untuk menunjukkan signifikasi tahap kedua. Hal tersebut menggambarkan interaksi ketika tanda bertemu dengan perasaan atau emosi pembaca dan nilai-nilai sosialnya. Konotasi mempunyai makna yang subjektif atau intersubjektif. Denotasi adalah apa yang digambarkan tanda terhadap sebuah objek, sedangkan konotasi adalah bagaimana menggambarkannya. Pada signifikansi tahap kedua yang berhubungan dengan isi, tanda bekerja melalui mitos. Mitos adalah bagaimana kebudayaan memahami aspek tentang realitas atau gejala alam. Keseluruhan tanda dalam denotasi berfungsi sebagai penanda pada konotasi atau mitos. Aspek subjektif

\footnotetext{
${ }^{6}$ Alex Sobur, Semiotika Komunikasi, (Bandung : PT. Remaja Rosdakarya, 2013), hlm. 69.

7 Semiotika Roland Barthes. www.kapanpunbisa.blogspot.com. diakses pada 20 Maret 2020
} 
berkaitan dengan kemampuan artistik dan daya kreativitas yang dibentuk oleh kebudayaan, mitos, kepercayaan, ideologi atau ketidaksadaran itu sendiri. ${ }^{8}$ Terdapat tiga pola yang ditemukan dalam mitos. Yaitu penanda, petanda dan tanda. Meski begitu, mitos adalah suatu sistem yang janggal karena mitos dibentuk dari semiologis yang telah eksis sebelumnya, mitos merupakan sistem semiologis tatanan kedua.

Mengutip Engels, Barthes mengatakan kesatuan sebuah eksplanasi tidak bisa didasarkan pada amputasi salah satu pendekatan didasarkan pada koordinasi dialektis terhadap ilmu-ilmu yang digunakan. Sebagai bagian dan semiologi maka mitos merupakan bagian dan ideologi karena ia merupakan ilmu sejarah, ia mempelajari gagasan dalam bentuk-bentuk. ${ }^{9}$ Menurut Barthes dalam Iskandar dan Lestari. Mitos kontemporer merujuk pada beberapa pendapat ilmuan. Diantaranya

1. Mitos nyaris sama dengan istilah representasi kolektif yang diajukan Emile Durkheim. Ia muncul dalam bentuk ujaran-ujaran anonim dalam media massa, dunia periklanan dan apa saja yang dikonsumsi massa. Mitos adalah sesuatu yang dideterminasi oleh wacana sosial, ia merupakan refleksi.

2. Dalam pandangan Karl Marx, mitos terjadi ketika kultur dijungkirbalikkan menjadi natural atau sebaliknya ketika kualitas sosial, kultural, ideologis dan historis terbalik menjadi natural.

3. Mitos kontemporer bersifat diskontinu. Mitos ini tidak lagi hadir dalam bentuk narasinarasi panjang dengan format baku, tetapi hanya dalam bentuk wacana.

4. Karena merupakan bentuk ujaran, mitos kontemporer masuk dalam cakupan semiotika dengan sistem semantiknya, maka denotatif dan konotatif. ${ }^{10}$

\section{Objek Penelitian}

Objek penelitian ini adalah 5 (lima) teks artikel di portal Wolipop pada fitur hijab konten hijab profile. Inilah objek penelitian selengkapnya,11

\footnotetext{
8 Yasraf Amir Piliang, Hipersemiotika, Tafsir Cultural Studies Atas Matinya Makna, (Yogyakarta : Jalasutera, 2018). hlm. 223.

9 Roland Barthes, Membedah Mitos-Mitos Budaya Massa: Semiotika atau Sosiologi Tanda, Simbol, dan Representasi, Penerjemah. (Yogyakarta: Jalasutera, 2007). hlm. 300.

10 Dudi Sabil Iskandar dan Rini Lestari, "Analisis Semiotika Roland Barthes pada Jurnalisme Online", Jurnal Prodi Ilmu Komunikasi, Vol. 4, No. 2, 2015, hlm. 72.
} 


\begin{tabular}{|c|c|c|c|}
\hline No & Foto Artikel & Judul Artikel & Edisi \\
\hline 1. & & $\begin{array}{l}\text { Sivia Azizah : Dari Blink kini jadi } \\
\text { Hijabers Hypebeast }\end{array}$ & $\begin{array}{l}\text { Jum'at, } 27 \\
\text { September } \\
2019\end{array}$ \\
\hline 2. & & $\begin{array}{l}\text { Inspiratif, kisah Atlet Angkat Besi } \\
\text { Berhijab pertama yang bergelar Doktor }\end{array}$ & $\begin{array}{l}\text { Rabu, } 14 \\
\text { Agustus } 2019\end{array}$ \\
\hline 3. & & $\begin{array}{l}\text { Cerita Lindswell Kwok bisnis busana } \\
\text { muslim setelah mualaf dan pensiun } \\
\text { wushu }\end{array}$ & $\begin{array}{l}\text { Minggu, } 12 \\
\text { Mei } 2019\end{array}$ \\
\hline 4. & & $\begin{array}{l}\text { Perjuangan pemain golf berhijab di } \\
\text { Amerika, tak menyerah meski di Bully }\end{array}$ & $\begin{array}{l}\text { Senin, } 22 \text { April } \\
2019\end{array}$ \\
\hline 5. & & $\begin{array}{l}\text { Cerita mualaf cantik asal Jepang, } \\
\text { temukan tujuan dalam Islam }\end{array}$ & $\begin{array}{l}\text { Selasa, } 09 \text { April } \\
2019\end{array}$ \\
\hline
\end{tabular}

Sumber: Data primer, 2020

\section{HASIL DAN PEMBAHASAN}

Realitas yang diciptakan media adalah realitas simbolik hasil produk atau rekayasa para pengelola (redaksi, wartawan, produser, dan semua orang yang bekerja di media). Eriyanto menyebutkan bahwa pekerjaan media pada hakekatnya adalah mengonstruksi realitas, dan isi 
media adalah hasil karya para pekerja media mengonstruksi berbagai realitas yang dipilihnya. ${ }^{12}$ Realitas yang dibentuk media ini dianggap sebagai kebenaran oleh audiens. Padahal menurut Paul Watson (konsep kebenaran yang dianut media massa bukanlah kebenaran sejati, tetapi sesuatu yang dianggap masyarakat sebagai kebenaran, dengan kata lain kebenaran hasil bentukan media massa. Isi media pada hakekatnya adalah hasil konstruksi realitas dengan bahasa sebagai perangkat dasarnya. Hamad mengungkapkan dalam proses konstruksi realitas bahasa adalah unsur utama, ia merupakan instrumen pokok untuk menciptakan realitas. ${ }^{13}$

Begitu pula portal wollipop mengkontruksi perempuan brhijab yang di kemas dalam hijab profile. Berdasarkan hasil penelitian pada 5 konten hijab profile, pada portal Wolipop, terdapat beberapa temuan sebagai berikut :

Gambar 1. Artikel 'Sivia Azizah : Dari Blink kini jadi Hijabers Hypebeast'

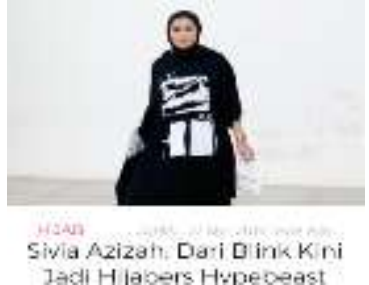

Gambar a.

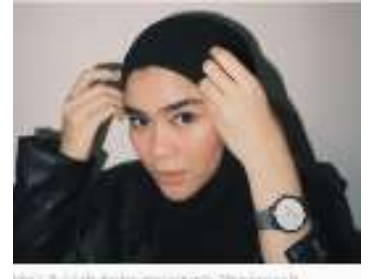

Gambar b.

Sumber: www. wolipop.com pada edisi Jum'at, 27 September 2019

Sivia Azizah merupakan mantan personel Blink yang memiliki talenta di dunia hiburan dan tarik suara. Setelah memilih untuk berkarir sendiri sejak 2017 dia memutuskan untuk menjadi hijabers, karena menurutnya sudah waktunya memakai hijab dan menutup aurat, simpel dan sesuai dengan kemauannya sendiri. Sivia lebih dikenal sebagai selebgram hijab SWAG atau Hypebeast dan influencer hijab yang selalu tampil dengan sneakers. Via tidak ambil pusing dengan perkataan netizen yang berkomentar tentang rambutnya yang masih kelihatan. Diakhir artikel disampaikan bahwa Sivia akan merilis single terbaru nya berjudul New York yang menceritakan keluar dari zona nyaman. ${ }^{14}$

Foto pada artikel ini, terlihat pada Gambar a. Sivia mengenakan baju berwarna hitam bercorak putih dan hijab berwarna hitam, menatap tajam kedepan, memegang pouch berwarna putih, dan memakai jam tangan berwarna gold. Serta pada gambar b. Sivia masih dengan tatapan tajam, menggunakan warna selaras dengan gambar a. yakni jaket kulit dan hijab hitamnya yang dipadukan dengan jam silver jari memegang ujung jilbab, serta tampak rambut

\footnotetext{
12 Eriyanto, Analisis Wacana: Pengantar Analisis Teks Media, (Yogyakarta: LkiS, 2002), hlm.75.

${ }^{13}$ Alex Sobur, Semiotika Komunikasi, (Bandung, Remaja Rosdakarya, 2001). hlm. 275.

${ }^{14}$ Gresnia Arela Febriani, Sivia Azizah: Dari Blink kini jadi Hijabers Hypebeast, Wolipop, 27 September 2019, https://wolipop.detik.com/hijab-profile/d-4724959/sivia-azizah-dari-blink-kini-jadi-hijabershypebeast, akses pada 20 Maret 2020.
} 
tipis di area dahinya ditambah dengan sentuhan lipstik nude dan make up tipis. Selain itu sivia juga dikenal sebagai Hypebeast dan influencer hijab, maka portal wollipop menggambarkan sosok yang saat ini digemari oleh perempuan berhijab diusia remaja adalah seperti Sivia.

Berdasarkan dari pemaknaan denotasi tersebut, menggambarkan bahwa Sivia merupakan sosok perempuan yang terlihat tomboy dengan gaya monokrom (yang digambarkan pada dominan baju yang dia kenakan yakni hitam dan putih). Foto yang diambil secara potret menunjukkan bahwa Sivia adalah upaya portal wolipop agar pembaca fokus pada Sivia saja. Pemilihan aksesoris jam tangan gold dan silver yang memberi kesan mewah dan elegan pada penampilan Sivia. Selain itu pemilihan pouch juga mendukung bahwa Sivia adalah gadis yang simpel. Sivia tampak percaya diri dengan keputusan berhijab ditunjukkan dengan tatapan mata tajamnya. Julukannya sebagai hijabers SWAG dan Hypebeast yang identik dengan snakers menggambarkan bahwa Sivia adalah perempuan yang memiliki kelebihan diantara perempuan seusianya yang asik dengan dunia percintaan, tugas, bersenang-senang, dan bergensi.

Berdasarkan konsistensi warna baju yang dikenakan, Sivia ingin menunjukkan bahwa dia beridiologi monokrom, sebagai perempuan yang memiliki ciri khas berbeda dari kebanyakan, sehingga memiliki ciri khas tersendiri dari setiap penggemarnya, dalam hal ini portal wollipop mengkontruksikan seorang perempuan berhijab akan lebih mudah diterima jika memiliki ciri khas yang dominan. Penggunaan sneakers yang menjadi ciri khasnya bukanlah semata seleranya, namun Sivia ingin menunjukkan bahwa sosok puplic figur yang mampu memberikan semangat kepada pecinta sneakers pula. Selanjutnya mengenai komentar Sivia yang dikemas oleh portal wollipop, bahwa tidak mengambil pusing netizen yang menegur rambutnya yang masih tampak ketika berhijab menggambarkan dirinya berhijab untuk menunjang eksistensi diri. Maka dalam artikel ini koten hijab profile pada portal wollipop mengkonstruksi perempuan berhijab akan memiliki eksistensi jika memiliki ciri khas dalam berhijab.

Gambar 2. Artikel ‘Inspiratif, kisah Atlet Angkat Besi Berhijab pertama bergelar Doktor’

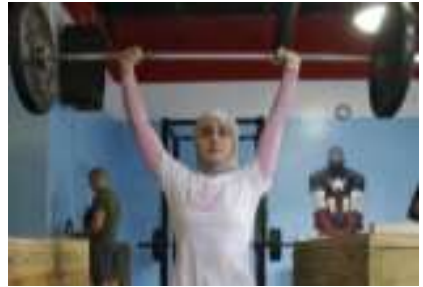

Gambar a.

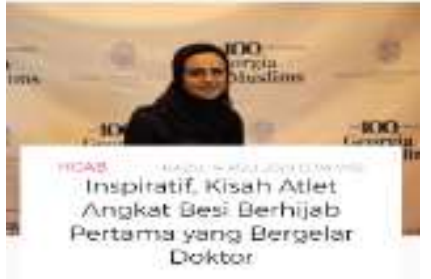

Gambar b.

Sumber : www.wolipop.com pada Rabu, 14 Agustus 2019 
Kulsoom Abdullah, berdarah Pakistan-Amerika, mendobrak dominasi pria pada dunia olahraga terutama angkat besi yang mengutamakan kekuatan fisik. Karirnya di dunia angkat besi sudah ditekuni sejak lulus sekolah, karena mau melatih daya tahan tubuh dan kekuatan otot. Walaupun berhasil meraih gelar doktor dalam bidang teknik, dia tetap menekuni bidang angkat besi, yang juga mendapat dukungan dari keluarga. Diakhir artikel dijelaskan bahwa Kulsoom kerap mendapatkan pertanyaan mengenai kenyamanannya berhijab saat latihan. ${ }^{15}$

Foto dalam artikel ini, terlihat pada gambar a. Perempuan yang mengenakan baju dan hijab berwarna hitam, senyum tipis dengan ketenangan dan di belakangnya terdapat spanduk berwarna putih polos yang bertuliskan the 100 Influintial Georgia Muslims. Sedangkan pada gambar b. tampak seorang perempuan berhijab yang tampak gagah dan yakin mengangkat barbel dengan kedua tangan nya, serta dibelakangnya terdapat satu orang laki-laki yang seolah sibuk dengan kegiatan nya dan sebuah gambar kartun superhero yang tampak gagah.

Berdasarkan makna denotasi tersebut menggambarkan bahwa perempuan berhijab yang bergelar doktor tersebut berasal dari kalangan ekonomi kelas atas yang mementingkan pendidikan, penggambaran baju dan hijab berwarna hitam melambangkan kekuatan dan kesan elegan yang dimilikinya, yang dibalut dengan kelembutan dari senyuman yang dilontarkannya. Selain itu background yang bertuliskan the 100 influintial Georgia muslims, portal Wolipop ini menjelaskan bahwa perempuan berhijab ini berasal dari negara yang minoritas muslim namun berhasil menorehkan prestasi sebagai binaragawati angkat besi, dimana selama ini banyak yang menganggap olahraga angkat besi bukanlah olahraga yang tepat untuk perempuan, karena perempuan dianggap memiliki kekuatan yang lemah, harus bersikap lemah lembut, dan selalu memperhatikan kecantikan dan keindahan seluruh tubuh nya. Diperkuat dengan gambar $b$. perempuan tersebut dengan yakin mengangkat barbel yang cukup besar dengan kedua tangannya, juga terdapat seorang lelaki yang tidak memperhatikan apa yang perempuan berhijab itu lakukan, menggambarkan bahwa perempuan tersebut bukan pertama kali melakukan hal tersebut ditempat itu. Gambar kartun superhero gagah yang terdapat di sana juga menggambarkan bahwa perempuan tersebut juga memiliki kemampuan, kekuatan yang tidak kalah dengan binaragawan angkat besi yang ada di sana.

Meskipun dalam teksnya juga dijelaskan bahwa perempuan berhijab tersebut sering mengalami intimidasi atas hijab yang dia kenakan karena dianggap akan membuat gerah, serta diceritakan bahwa adanya penolakan atas keikutsertaannya sebagai peserta berhijab pada Olimpiade tahun 2010, namun Kulsoom tidak menyerah dan meminta agar peraturan direvisi,

15 Gresnia Arela Febriani, Inspiratif, kisah Atlet Angkat Besi Berhijab Pertama yang Bergelar Doktor, Wolipop, 14 Agustus 2019, https://wolipop.detik.com/hijab-profile/d-4665074/inspiratif-kisah-atletangkat-besi-berhijab-pertama-yang-bergelar-doktor, akses pada 20 Maret 2020. 
dan akhirnya Kulsoom berhasil menjadi perempuan berhijab pertama yang mengikuti olimpiade angkat besi, tampak disini portal Wolipop menggambarkan bagaimana usaha dan kegigihan perempuan berhijab tersebut untuk dapat berkompetisi dan memiliki kesempatan dalam olimpiade angkat besi.

Portal wolipop menggambarkan bahwa perempuan berhijab mampu merubah kebijakan yang deskriminatif menjadi kebijakan yang adil. Yakni telah terjadi pergeseran kelas menjadi kebijakan publik yang feminis. Kebijakan publik yang feminis, maka pihak-pihak yang mempunyai otoritas dalam membuat kebijakan harus mempunyai perspektif feminis atau perspektif gender. ${ }^{16}$ Maka portal wollipop melalui kisah Kulsoom ingin mengkontruksikan bahwa perempuan berhijab mampu membuat pihak yang mempunyai otoritas kebijakan yang deskriminatif terhadap eksistensi diri perempuan mejadi kebijakan berspektif gender.

Gambar 3. Artikel ‘Cerita Lindswell Kwok Bisnis Busana Muslim setelah Mualaf dan Pensiun Wushu'

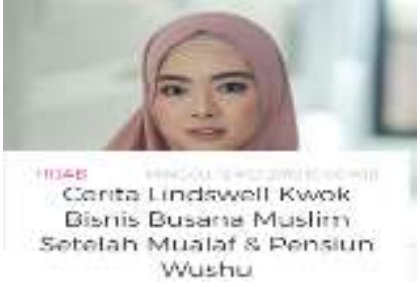

Gambar a.

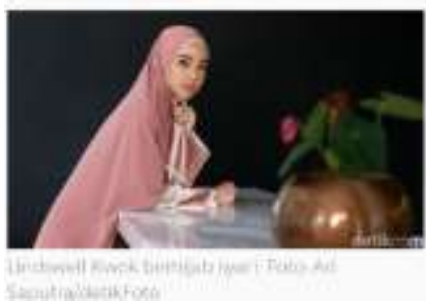

Gambar b.

Sumber : www.wolipop.com pada Minggu, 12 Mei 2019

Lindswell Kwok merupakan peraih mendali emas cabang olahraga Wushu di Asean Games 2018. Menjadi mualaf dan menikah dengan Achmad Haulaefi, sahabatnya sesama atlet Wushu. Setelah pension untuk mengisi waktu senggang Lindswell mengembangkan bisnis di bidang fashion, yang terinspirasi karena kebutuhan untuk dipakai sendiri, background sebagai seorang atlet membuat dia memiliki karakter tersendiri dalam memilih bahan berdasar adem dan ringkes, yang belakangan dikembangkan kualitas bahan yang nyaman, sejuk dengan desain yang simpel. Orang yang tidak berhijab pun bisa memakai abaya. Hal ini dilakukan untuk mengenalkan bahwa perempuan cantik tidak harus pakai baju minim, baju ketat, memperlihatkan lekuk tubuhnya. Abaya tersebut dibandrol dari Hary Rp. 630.000.17

${ }^{16}$ Lusia Palulungan dan M. Ghufran H. Kordi. K. "Advokasi Kebijakan Publik Yang Feminis; Belajar Dari Kota Parepare \& Ambon" dalam Konferensi Internasional Feminisme: Persilangan Identitas, Agensi dan Politik (20 Tahun Jurnal Perempuan. () Jurnal Perempuan, 2016 Yayasan Jurnal Perempuan, Jakarta. hlm. 195.

17 Silmia Putri, Cerita Lindswell Kwok Bisnis Busana Muslim setelah Mualaf dan Pensiun Wushu , Wolipop, 12 Maret 2019, https://wolipop.detik.com/hijab-profile/d-4545954/cerita-lindswell-kwokbisnis-busana-muslim-setelah-mualaf--pensiun-wushu, akses pada 20 Maret 2020. 
Foto dalam artikel ini, menggambarkan betapa anggunnya Lindswell mengenakan baju abaya dengan hijab panjang berwarna pink, dengan hiasan make up yang menambah keindahan, keanggunan, dan kecantikannya, dengan background foto hanya berwarna hitam membuat Lindswell tampak dominan dengan baju abaya dan hijabnya yang berwarna pink. Selain Lindswell yang tampak menyandarkan tubuhnya di sebuah meja berwarna silver tersebut, terdapat bunga pink dengan daun yang lebar didalam vas berwarna coklat. Pada artikelnya juga dijelaskan bahwa Lindswell mampu membuat trend sendiri yang dikembangkan dari kemauanya untuk menjadi bisnis.

Berdasarkan makna denotasi di atas, portal wollipop mengambarkan bahwa, vas yang berisikan bunga berwarna pink dengan daun hijau yang segar, seolah menggambarkan Lindswell telah tepat memilih agama islam sebagai wadah (dilambangkan oleh vas) untuk meberikan kesejukan, kesegaran, kemampuan untuk terus tumbuh dan memberikan manfaat bagi sekitar (dilambangkan oleh daun) serta dalam hati dirinya mampu menyajikan keindahan yang dapat dilihat dan dinikmti karyanya oleh banyak orang (dilambangkan dengan bunga yang tampak mekar diantara daun yang lebih besar).

Jika di tilik dari dominan warna yang ditampilkan, yakni warna pink, merupakan hasil dari paradigma di masyarakat yang memandang sebagai warna yang digunakan perempuan untuk membentuk identitas diri. Namun berdasarkan sejarah, bentuk feminitas pada warna pink merupakan hasil dari proses transformasi makna yang semula berkonotasi maskulin, yang terjadi di Amerika sebanyak 3 kali antara tahun 1940 hingga akhir tahun 1970. Transformasi makna yang pertama terjadi saat perang dunia I dan II, terjadi transformasi sosial di masyarakat yang berpengaruh terhadap perubahan pemaknaan warna pink dari maskulin menjadi feminim. Transformasi makna yang kedua terjadi pada pertengahan dekade 1950, terjadi perubahan gaya hidup yang revolusioner hasil dari kemajuan ekonomi di Amerika, yang menyebabkan terdapat dua pemaknaan femininitas pada warna pink. Tranformasi makna yang ke tiga terjadi antara tahun 1960-1970an, pemaknaan warna pink kemudian berkonotasi feminim dan cenderung bersifat masif hingga saat ini, dampak dari isu-isu dan gerakan sosial yang berkembang, diantaranya gerakan feminisme, isu perubahan kondisi sosial dan perilaku sosial. Sebab sebenarnya warna pink yang diunakan pada seorang perempuan merupakan simbol ekspresi sisi maskulinitas dalam diri perempuan yang direproduksi menjadi simbol femininitas baru. ${ }^{18}$

18 Moh. Faishal faudy, "Pergeseran Makna Warna Pink dari Maskulinitas menjadi Femininitas di Amerika Serikat 1940-1970", Jurnal Desain Interior, Vol. 2, No. 2, 2017, Lembaga Penelitian dan Pengabdian kepada Masyarakat, ITS. hlm. 97-104. 
Maka dalam artikel konten hijab profile melalui kisah Lindswell portal wollipop mengkonstruksi perempuan berhijab bebas untuk menunjukkan eksistensi dirinya harus menyertakan kenyamanan agar bisa menghadirkan peluang bisnis yang menjanjikan. Berdasarkan sejarah dominasi warna pada artikel ini menggambarkan bahwa dibalik balutan kelembutan warna pink, seorang perempuan mampu menaklukkan apa yang menjadi keinginannya. Selain itu Wolipop juga menggambarkan bahwa untuk mendapatkan kenyamanan dalam berhijab, diperlukan pemilihan bahan yang tepat, dengan bandrol harga yang tergolong mahal.

Gambar 4. Artikel ‘Perjuangan Pemain Golf Berhijab di Amerika, tak menyerah meski di Bully'

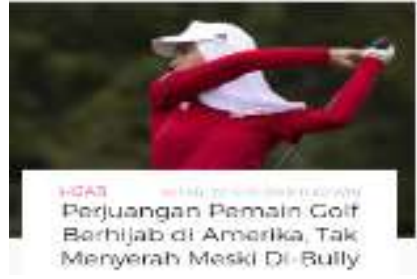

Gambar a.

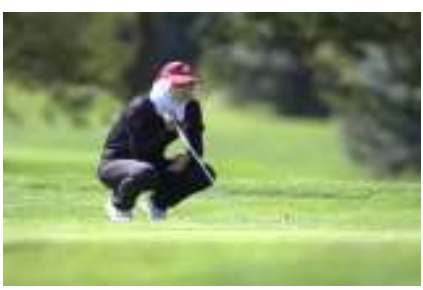

Gambar b.

Sumber: www.wolipop.com pada Senin, 22 April 2019

Di awal artikel dijelaskan bahwa, tidak semua hijabers memiliki kesempatan yang sama untuk menekuni profesinya. Khususnya di negara minoritas muslim seperti di Amerika Serikat. Sebab hijab menjadi isu sensitif, dan hijabers disana harus berjuang untuk membuktikan bahwa hijab bukan simbol penindasan dan terorisme. Noor Ahmed yang menjadi kontestan berhijab pertama pada turnamen American Junior Golf Association di Las Vegas. Hal tersebut mengantarkannya memperoleh beasiswa dan dapat pelatihan golf dan bergabung dalam tim golf Nebrashka. Di akhir artikel dijelaskan bahwa Ahmed sering mendapatkan perkataan bahwa muslimah (berhijab) tidak seharusnya bermain golf, tidak berhak tinggal di Amerika, perkataan itu sempat mengganggunya, tapi tidak menghentikannya. ${ }^{19}$

Foto dalam artikel tersebut, Menggambarkan seorang perempuan berhijab yang mahir bermain golf, diperkuat dengan seragam berwarna dominan merah dan putih melambangkan keberaniannya, sedang mengayunkan pemukul golf. Sedangkan pada gambar b. Tampak perempuan tersebut duduk setengah jongkok dengan menahan tubuh nya dengan pemukul golf, serta menatap kedepan seolah menatap bola golf yang telah dipukul sebelumnya,

19 Silmia Putri, Perjuangan pemain golf berhijab di Amerika, tak menyerah meski di Bully, Wolipop, 22 April 2019,https://wolipop.detik.com/hijab-profile/d-4519690/perjuangan-pemain-golf-berhijab-diamerika-tak-menyerah-meski-di-bully, akses pada 20 Maret 2020. 
perempuan berhijab itu tampak mengenakan baju seragam berwarna hitam di Padang rumput. Selain itu dijelaskan pada isi artikel bahwa perempuan tersebut sering mendapatkan pernyataan yang menyudutkan dirinya karena memakai hijab, hal tersebut menunjukkan bahwa perempuan yang mengenakan hijab di Negara yang minoritas mulsim, wanita berhijab sering mendapatkan deskriminasi, namun wanita berhijab tersebut mampu mendongkrak deskriminasi, dengan prestasi yang ditorehkannya melalui olahraga golf.

Berdasarkan makna denotasi diatas, portal wolliop menggambarkan bahwa Negara minoritas muslim kerap kali menganggap hijab adalah simbol dari teroris, oleh sebab itu masyarakat muslim minoritas mendapat deskriminasi, namun dalam artikel ini portal wollipop mengkontruksikan bahwa perempuan berhijab meskipun di Negara muslim minoritas, tetap bisa eksis dengan keberanian, berpendirian tangguh dan berprestasi.

Gambar 5. Artikel ‘Cerita mualaf cantik asal Jepang, temukan tujuan dalam Islam'

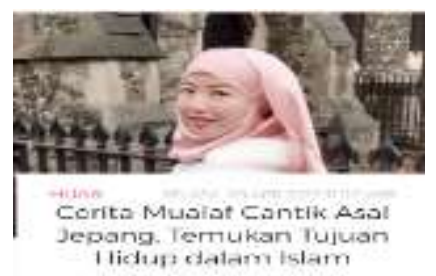

Gambar a.

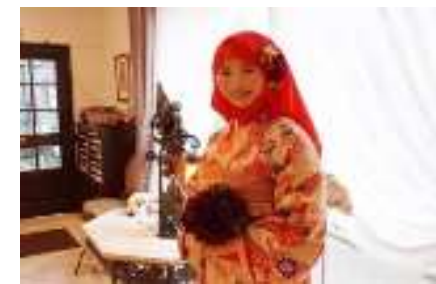

Gambar b.

Sumber : www.wolipop.com pada Selasa, 09 April 2019

Di awal artikel dijelaskan bahwa perempuan asal Jepang bernama Nur Arisa Maryam (nama baru), merasakan hidup tanpa tujuan, yang membuat nya stres dan bosan. Dia mengenal muslim dari lingkungan di kampusnya mulai dari teman, dosen bahkan teman klub dance nya juga banyak yang muslim. Menurutnya cara berfikir Islam sangat indah dan selalu mengembalikan pada Tuhan, hal tersebut yang membuat nya antusias pada muslim. Meskipun tidak mendapat dukungan dari keluarga dan teman-temannya, dia tetap berusaha keputusannya dapat diterima. Di akhir artikel dijelaskan bahwa postingan pada Instagramnya kerap mencuri perhatian karena gaya hijab dan motivasi yang di sampaikan, terbukti dengan dia memiliki lebih dari 80 ribu followers. ${ }^{20}$

Foto dalam artikel tersebut, menggambarkan cantik adalah perempuan yang mengenakan pakaian berwarna feminim seperti pink dan orange serta bunga-bunga khas baju kimono, mengenakan jaket berbulu berwarna putih yang tampak elegan, penambahan lipstik, berkulit putih, serta selalu senyum, Selain itu juga dijelaskan bahwa perempuan berhijab tersebut

20 Silmia Putri, Cerita mualaf cantik asal Jepang, temukan tujuan dalam Islam, Wolipop, 09 April 2019,https:/ / wolipop.detik.com/hijab-profile/d-4502541/cerita-mualaf-cantik-asal-jepang-temukantujuan-hidup-dalam-islam, akses pada 20 Maret 2020. 
merupakan mualaf maka perempuan tersebut berkewajiban untuk menjalankan semua perintah agama islam, terasuk tentang berhijab dan berhak dapat zakat. Perempuan tersebut merasa menemukan tujuan hidupnya setelah mempelajari agama Islam. Selain itu wollipop juga menggambarkan bahwa perempuan berhijab ini, berhasil menarik perhatian dunia karena sering mengunggah foto dan kata-kata memotivasi.

Berdasarkan makna denotasi tersebut portal wollipop, menggambarkan bahwa tanpa mengurangi eksistensinya, kimono yang merupakan pakaian tradisional masyarakat Jepang dapat dipadukan dengan hijab, meskipun biasanya perempuan yang menggunakan kimono menata rambutnya dengan beberapa pilihan model dan hiasan kepala. Selain itu portal wollipop juga mengkontruksikan bahwa islam merupakan agama yang penuh dengan hidayah, sebab perempuan yang awalnya merasa tidak memiliki tujuan hidup, setelah menjadi mualaf mampu menginspirasi dan memberikan motivasi kepada banyak orang.

\section{KESIMPULAN}

Komunikasi keberagamaan di Rama Agung dinilai mumpuni dan menjadi penting untuk diangkat di tengah isu perpecahan keindonesiaan (darurat terorisme, radikalisasi, dan rasisme) Komunikasi yang terjalin di antara umat beragama yang terjadi secara alamiah dan rekayasa sosial telah merubah relasi antar manusia dengan lingkungan. Kami meyakini komunikasi beserta forum yang sengaja atau tidak sengaja dibentuk telah menjadi penghubung. Komunikasi digelar melalui situasi informal dan formal, sehingga menjadi sebuah forum pembicaraan atas sebuah topik yang dinilai penting di desa.

Kami menemukan tiga starting poin yang menjadi modal sosial kerekatan umat beragama di Rama Agung: sistem nilai yang terjaga secara turun temurun dan interaksi antar nilai yang baik di lingkungan, aturan tertulis, dan peran tokoh agama. Pola komunikasi yang muncul berawal dari situasi informal yakni seseorang mulai menyampaikan ide. Kemudian, ide ditanggapi oleh orang lain dan memungkinkan untuk mengalami dialektika untuk beberapa waktu. Ide yang dinilai sudah siap akan disampaikan dalam forum formal. Pada forum ini akan dilakukan pengembangan dan eksekusi ide. Forum komunikasi berasal dari forum formal seperti rapat RT, RW, Balai Desa, Karang Taruna, sedangkan forum informal dapat terjadi dimanapun. Mayoritas forum formal terjadi dalam kondisi santai dan penuh kebersamaan ala situasi desa. Pada akhirnya, kami menyarankan untuk studi masa depan untuk perlu melihat lebih dalam menggunakan studi naratif agar dapat tergambarkan dengan jelas bagaimana komunikasi menjadi jembatan desa wisata religi yang diselenggarakan oleh keberagaman agama. 


\section{DAFTAR RUJUKAN}

Ali, Yusuf Faisal., “Upaya Tokoh Agama Dalam Mengembangkan Sikap Toleransi Antar Umat Beragama," Untirta Civic Education Journal, Vol. 2, No. 1, 2017.

Aryani, Sandra Woro, Sunarti Sunarti, dan Ari Darmawan., “Analisis Dampak Pembangunan Pariwisata pada Aspek Ekonomi dan Sosial Budaya Masyarakat: Studi Kasus pada Desa Wisata Bejiharjo." Jurnal Administrasi Bisnis, Vol. 49, No. 2, 2017.

Blakemore, Scott., "Faith-based Diplomacy and Interfaith Dialogue," Brill Research Perspectives in Diplomacy and Foreign Policy, Vol. 3, No. 2, 2019.

Creswell, Jhon W., Penelitian Kualitatif dan Desain Riset: Pemilihan di antara Lima Pendekatan. Yogyakarta: Pustaka Pelajar, 2015.

Crouch, Melissa., “Judicial Review and Religious Freedom: The Case of Indonesian Ahmadis.” Sydney Law Review, Vol. 34, 2012.

Fealy, Greg., "Bigger than Ahok: Explaining the 2 December Mass Rally." http://indonesiaatmelbourne.unimelb.edu.au/bigger-than-ahok-explaining-jakartas-2december-mass-rally/

Freedom House, "Indonesia", Freedom in the World (2013), https://freedomhouse.org/report/freedom-world/2013/indonesia.

Hasan, Noorhaidi., "Religious Diversity and Blasphemy Law: Understanding Growing Religious and Intolerance in Post-Suharto Indonesia." Al-Jāmi'ah: Journal of Islamic Studies, Vol. 55, No. 1, 2017.

Heiling, Robert M., "Conflict Resolution in Aceh in Light of Track One and a Half Diplomacy," Austrian Journal of South-East Asian Studies, Vol 2, No. 1, 2008.

Hermawan, Hary., "Dampak Pengembangan Desa Wisata Nglanggeran terhadap Ekonomi Masyarakat Lokal." Jurnal Pariwisata, Vol. 3, No. 2, 2016.

Hernawan, Wawan., "Komunikasi Antarumat Berbeda Agama (Studi Kasus Sikap Sosial dalam Keragaman Beragama di Kecamatan Cigugur Kabupaten Kuningan Jawa Barat)," Jurnal Kom dan Realitas Sosial, Vol 1, No 1, 2010.

Hicks, Jacqueline., "Heresy and Authority: Understanding the Turn against Ahmadiyah in Indonesia." South East Asia Research, Vol. 22, No. 3, 2014.

LSI. “Kerentanan terhadap Radikalisme Sosial-Keagamaan. Temuan survei: 26 Maret - 6 April 2010." Jakarta: Lembaga Survei Indonesia.

LSI. “Kerentanan terhadap Radikalisme Sosial-Keagamaan. Temuan Survei: Juni-Juli 2011." Jakarta: Lembaga Survei Indonesia.

LSI. "Potensi Radikalisme dan Intoleransi Sosial-Keagamaan di Kalangan Muslim Indonesia. Temuan Survei: 30 Maret - 9 April 2016." Jakarta: Lembaga Survei Indonesia. 
Madjid, Nurcholish., "Islamic Roots of Modern Pluralism: Indonesia Experience." Studia Islamika, Vol. 1, No. 1, 1994.

Masmudin, "Komunikasi Antar Umat Beragama di Kota Palopo," Jurnal Studi Agama dan Masyarakat, Vol 13, No 1, 2017.

Mietzner, Marcus dan Burhanuddin Muhtadi., "Explaining the 2016 Islamist Mobilisation in Indonesia: Religious Intolerance, Militant Groups and the Politics of Accommodation." Asian Studies Review, Vol. 42, No. 3, 2018.

Mulyana, Eldi., “Upaya Pemberdayaan Ekonomi, Sosial dan Budaya pada Masyarakat Melalui Pengembangan Bisnis Ekowisata." Business Innovation \& Entrepreneurship Journal, Vol. 1 No. 1, 2019.

Miles, Matthew B. dan Michael A. Huberman,, Qualitative Data Analysis: A Source Book of New Methods, London: Sage Publication, 1998.

Prasetyo, Laurentius Yananto Andi. “Peran Tokoh Lintas Agama dalam Menangkal Gerakan Radikalisme Agama dan Implikasinya terhadap Ketahanan Wilayah. Skripsi. Universitas Gajah Mada: Program Studi Ketahanan Nasional Sekolah Pascasarjana Universitas Gajahmada, 2013.

Prastiyo, Dibyo dan Budi Setiyono., "Analisis Strategi Pemberdayaan Masyarakat dalam Pengembangan Desa Wisata Cempaka." Journal of Politic and Government Studies, Vol 8. No. 3, 2019.

Prihanta, Wahyu, Amir Syarifuddin, dan Achmad Muhib Zainuri., "Pembentukan Kawasan Ekonomi melalui Pengembangan Ekowisata Berbasis Masyarakat." Jurnal Dedikasi, Vol. 14, 2017.

Risman, Apep, Budhi Wibhawa, dan Muhammad Fedryansyah. "Kontribusi Pariwisata terhadap Peningkatan Kesejahteraan Masyarakat Indonesia." Prosiding Penelitian dan Pengabdian Masyarakat, Vol 3, No. 1, 2016.

Rokeach, Milton., “The Nature of Human Values”. New York: The Free Press, 1973.

Saputra, Hendra, Rudianto Rudianto, Dwikie Setiawan, Rudy Agung Nugroho., Desa Wisata Hidroponik sebagai Upaya Pemberdayaan Masyarakat." Jurnal Pengabdian Masyarakat, Vol. 24, No. 1, 2018.

Setara Institut. "Intolerance Supremacy: The Report of Condition of Freedom of Religion/ Belief and Religious Minorities in Indonesia in 2016." Jakarta: Pustaka Masyarakat Setara.

Soedirgo, Jessica., "Informal networks and religious intolerance: how clientelism incentivizes the discrimination of the Ahmadiyah in Indonesia." Citizenship Studies, Vol. 22, No. 2, 2018. Wahid, Abdurrahman dan Charles H. Tayor., "A Tradition of Tolerance in Indonesia Offers Hope." Foreign Service Journal, 2008. 
Wahid Foundation. "Kemerdekaan Beragama/Berkeyakinan." Temuan Survei 2016. hlm. 15; LaKIP. "Survei Radikalisme di Kalangan Pelajar." Temuan survei 2010 dalam https://www.bbc.com/indonesia/berita_indonesia/2016/02/160218_indonesia_radikali sme_anak_muda

Yani, Yanita Pricilia dan Siti Muti'ah Setiawan., Proses Penyelesaian Konflik Aceh Melalui Mou Helsinki: Keberhasilan Pemerintah Indonesia Membuat GAM Menerima Konsep SelfGovernment," Thesis, Yogyakarta: Universitas Gadjah Mada. 